\title{
Editorial
}

\section{Impaired control: a look at the laying brick of pathological gambling}

\author{
Prejuizo de controle: um \\ exame dos alicerces do \\ jogo patológíco
}

When pathological gambling (PG) was first included in the DSM-III in 1980, its core element was described as a progressive difficulty for one's to limit his/her gambling behavior. This was popularized under the terminology "loss of control". Where does that notion come from?

Castellani described how gambling "excess" was first regarded as a vice and progressively evolved towards a disease. ${ }^{1}$ With the progressive legalization of gambling in North America, the former conception was challenged. In the 70s, a psychiatrist named Robert Custer opened the first treatment facility for gamblers and became a strong proponent of the inclusion of PG in the DSM. Custer's clientele was essentially formed by Gamblers Anonymous (GA) members. This particular sample seems to have strongly influenced the conceptualization of PG.

GA philosophy derives from the Alcoholics Anonymous ( $A A$ ) one, where alcoholism is viewed as a progressive and permanent disease. For alcoholics, even one drop of alcohol was believed to create a domino reaction that inevitably leads to binge drinking. With this perspective, control is impossible for alcoholics and one of the first steps when becoming active in the AA fraternity is to recognize the impossibility to control alcohol intake. The "loss of control" base of alcoholism was further popularized by Elvin Morton Jellineck, ${ }^{2}$ who developed the conceptualization of alcoholism which became the WHO official one. In the mid-70s, this view came under critics. Researchers found that even strongly dependent alcoholics managed to drink in a controlled way (e.g. Maisto \& Schefft ${ }^{3}$ ). The terminology changed to "impaired control", since control was seen as intermittently impaired rather than lost. Although this clarification was theoretically justified, it was criticized for its lack of testability.

Impaired control seems to be something evident, with good face validity. It is commonly reported by gamblers in treatment and actively sought by practitioners. Several researchers have already suggested that impaired control is an etiological factor for PG. Here lies a major hindrance to the evolvement of this concept: impaired control ends up as both an inferred manifestation and a developmental factor of PG, leading to circular reasoning. The idea that gambling is out of control stems from two observable phenomena: 1) On a long term basis, gambling leads to monetary losses for most gamblers, and in some instances, losses will lead to pervasive negative consequences; 2) The excessive behavior persists despite obvious harm. However, logically speaking, impaired control can be verified only after gambling has occurred and is essentially based on a gambler's verbal report. People find much easier to classify as poor control if one goes gambling and loses money. But what if he or she eventually wins?

Dickerson and O'Connor state that gambling impaired control must be disentangled from gambling harm, defining it as "an inability to consistently maintain preferred limits to expenditure of time and money on gambling". ${ }^{4}$ But where and when does one overstep the bounds of social gambling? To further understand 
impaired control, we have to separate the perception of impaired control from what actually happens when one gambles.

If gambling takes place within one's time and money limits, it is rather unlikely that gamblers will experience or report any problem about their wagering. On the other hand, if gambling hardship does happen, the perception of impaired control is highly probable to occur. Davies explains the loss of control discourse as a functional attribution for justifying one's socially questionable behaviour. ${ }^{5}$ Would it be more appropriate to label this phenomenon as a "Perception of impaired control" rather than a phenomenon in itself? Although insightful at a social level, this explanation does not say anything about the causes of the development of gambling problems.

We suggest it is necessary to shift our focus towards the "decisional process" that happens during gambling. Since money is a limited resource, the gambler will sooner or later be challenged by limits in disposable money and time. At this crucial moment, a decision needs to be taken. When the money shortage hits, would the gambler withdraw or borrow additional money to continue gambling? Or would he/she rather stop gambling? What are the factors that influence this decision-making process? Research suggests that various biological, cognitive, emotional and environmental factors influence its outcome. This view is opposed to the notion of a compulsion that "seizes" the unfortunate gambler. For operational purposes, the study of the decisionmaking process involving in situ gambling may prove more productive in understanding the development of pathological gambling than the more traditional view of compulsion and impaired control. Indeed, it is not possible to distinguish empirically an urge that is uncontrollable from one that is not yet controlled (Akers, as cited in Davies ${ }^{5}$ ).

Some questions have to be further explored: 1) How to identify abnormal reactions to gambling and how they evolve into perception of impaired control; 2) Besides time and money, what could be other indicators of poor decision-making while gambling? 3) What are the processes sustaining gambling even after the perception of impaired control takes place? Integration of knowledge from the fields of neuropsychology and behavioral economics seems necessary in order to renew our thinking about the development of PG. Maybe we also need to change some laying bricks of the construct of PG.

Michael Cantinotti, Robert Ladouceur Department of Clinical Psychology, University of Laval, Quebec, Canada

Hermano Tavares Department of Psychiatry, Universidade de São Paulo (USP), São Paulo (SP), Brazil
Financing: Michael Cantinotti received a scholarship from the Loterie Romande during his contribution to the paper.

Conflict of interests: Michael Cantinotti received a scholarship from the Loterie Romande during his contribution to the paper.

\section{References}

1. Castellani B. Pathological gambling: the making of a medical problem. Albany, NY: State University of New York Press; 2000.

2. Jellineck EM. The disease conception of alcoholism. New Haven, Conn.: Hill-house Press; 1960.

3. Maisto SA, Schefft BK. The constructs of craving for alcohol and loss of control drinking: Help or hindrance to research. Addict Behav. 1977;2(4):207-17.

4. Dickerson M, O'Connor J. Gambling as an Addictive Behaviour: Impaired Control, Harm Minimisation, Treatment and Prevention (International Research Monographs in the Addiction). Cambridge, Ma: Cambridge University Press; 2006.

5. Davies JB. Reasons and causes: understanding substance users' explanations for their behaviour. Human Psychopharmacology: Clinical and Experimental. 1996;11(S1):S39-S48. 